\title{
Endoskopisk kirurgi
}

\author{
Endoskopisk kirurgi i mage-tarm-kanalen ble utviklet i Japan i 1990- \\ årene som en minimalt invasiv metode for å fjerne svulster $\mathrm{i}$ en tidlig \\ fase med gastro- eller koloskop istedenfor med åpen eller laparosko- \\ pisk kirurgi. Fordelene er åpenbare. Pasienten spares for en større \\ operasjon, sykehuset sparer ressurser samt innleggelse i sengepost \\ og samfunnet sparer utgifter til sykmeldingsdager. Endoskopisk sub- \\ mukosal disseksjon regnes som den mest krevende teknikken, men \\ tillater presis disseksjon av store svulster. I 1999 utførte japaneren \\ Takuji Gotoda og hans team for første gang slike disseksjoner av tidlige \\ kreftsvulster i endetarmen med en diaterminål og et fleksibelt skop.
}

Begrepet endoskopisk kirurgi blir i noen sammenhenger benyttet som en fellesbetegnelse for en lang rekke prosedyrer som utføres både med fleksible og stive skop, inkludert laparoskopisk kirurgi, men disse blir i dag oftere erstattet av den mer moderne betegnelsen minimalt invasiv kirurgi. I denne artikkelen definerer vi derfor endoskopisk kirurgi som en variant av minimalt invasiv kirurgi utført med fleksible skop i mage-tarm-kanalen. Fjerning av stilkede polypper i mage-tarm-kanalen utføres i dag rutinemessig ved de fleste sykehus i Norge. Store, flate lesjoner med celleforandringer eller submukøse svulster er derimot blitt henvist til tradisjonell kirurgi. Med nye teknikker er det nå mulig å fjerne også disse endoskopisk. Utstyret som benyttes er enkelt og består av et gastro- eller koloskop med $\mathrm{CO}^{2}$ insufflator og spylepumpe samt ulike typer éngangsinstrumenter som føres inn gjennom arbeidskanalen. Utfordringen er at teknikkene er vanskelige å lære. Store pasientvolumer og en uttalt subspesialisering var forutsetninger for innføring av disse teknisk krevende metodene i Japan (1). En mer desentralisert sykehusstruktur med lavere pasientvolum og mindre subspesialisering er begrensende faktorer for implementering $\mathrm{i}$ vestlige land.

\section{Preoperativ diagnostikk}

Påvisning av kreft i preoperative biopsier vil som regel alltid være en kontraindikasjon mot endoskopisk reseksjon pga. risiko for spredning til lymfeknuter som da må fjernes kirurgisk med organreseksjon. Selv om overfladiske biopsier kun viser celleforandringer, bør man likevel vurdere risikoen for å finne kreft mer sentralt i svulsten. Ved å studere svulstens overflatestrukturer med skop med forstørrelsesfunksjon samt benytte farging av lesjonen eller filtrert lys, kan man ved å sammenholde disse opplysningene med form, størrelse og histologi si noe om risikoen for invasiv vekst $(2,3)$. I tillegg vil et såkalt positivt løftetegn som beskrevet nedenfor, være et avgjørende diagnostisk kriterium i første fase av vurderingen for endoskopisk

\section{Fjerning av overfladiske svulster}

I første omgang ble den endoskopiske kirurgien utviklet for å fjerne overfladiske svulster begrenset til mucosa. En grunnleggende teknikk er derfor å lage et såkalt submukosalt løft. Ved å injisere væske blandet med litt blåfarge i submucosa vil submucosa ekspandere og man skaper et sjikt under som man kan dissekere i (fig 1). I tillegg skapes det en trygg avstand til det underliggende muskelvegglaget som man ikke ønsker å skade. Det at mucosa løfter seg ved injeksjon av væske i submucosa, kalles et positivt løftetegn og vil være et bevis på at svulsten ikke vokser ned i muskellaget, noe som vanligvis vil være en kontraindikasjon mot endoskopisk kirurgi. Etter at svulsten er «løftet opp fra underlaget» med submukosal injeksjon, kan den enten fjernes med slynge eller med disseksjon. Endoskopisk reseksjon med slynge benevnes endoskopisk mucosareseksjon (EMR), mens disseksjon med små diatermiinstrumenter omtales som endoskopisk submukosal disseksjon (ESD) (e-tab 1).

I endetarm og tykktarm er det $\mathrm{i}$ vestlige land vanligst å benytte endoskopisk mucosareseksjon, da store svulster kan fjernes $\mathrm{i}$ deler (piecemeal) med liten risiko for residiv. Fordelene med endoskopisk submukosal disseksjon derimot, er at man får ut preparatet i ett stykke. Det gir enda mindre risiko for residiv, og man kan dissekere dypere og mer kontrollert i submucosa enn ved endoskopisk mucosareseksjon. På den reseksjon.

\section{Christian Rushfeldt}

christian.rushfeldt@unn.no

Avdeling for gastrointestinal kirurgi

Kirurgi, kreft og kvinnehelseklinikken

Universitetssykehuset Nord-Norge

Khanh Do-Cong Pham

Seksjon for gastroenterologi

Medisinsk avdeling

Haukeland universitetssykehus

Lars Aabakken

Klinikk for kreft, kirurgi og transplantasjon

Oslo universitetssykehus, Rikshospitalet

og

Medisinsk fakultet

Universitetet i Oslo

e-tab 1 finnes i Tidsskriftets elektroniske utgaver

\section{HOVEDBUDSKAP}

Endoskopisk kirurgi er en minimalt invasiv metode for fjerning av svulster $i$ en tidlig fase i hele mage-tarm-kanalen

Metoden sparer pasienten for arr, sårsmerter og fjerning av organer eller deler av organer og gir mulighet til å komme raskere tilbake $\mathrm{i}$ arbeid

Teknikkene tar tid å lære og det er viktig å gi mulighet for indremedisinere eller kirurger å oppnå tilstrekkelig trening og erfaring 

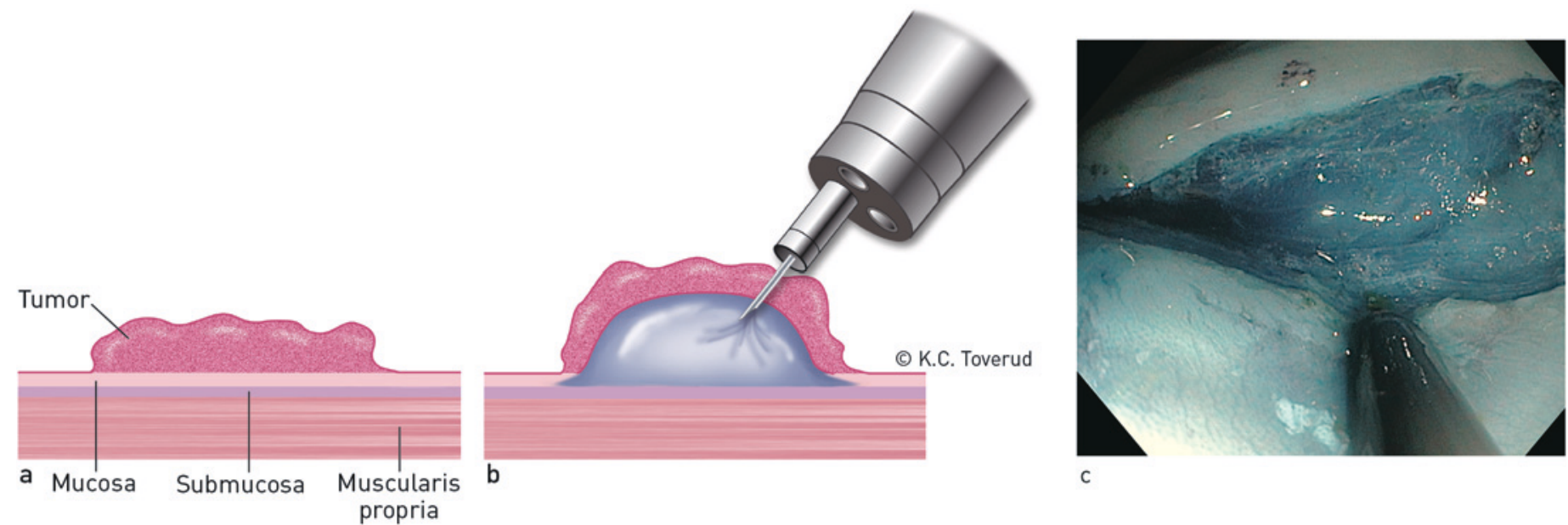

Figur 1 Submukosalt løft skapes ved å injisere en væske (her tilsatt blåfarge) i det submukosale sjiktet mellom muscularis propria og tumor som ligger $i$ mucosa la) slik at dette ekspanderer (b). Starten på en disseksjon i et tydelig ekspandert, blåfarget submukosalt sjikt fremstår her som unormalt fortykket (c)

annen side tar endoskopisk submukosal disseksjon lengre tid å utføre, er teknisk vanskeligere og øker risikoen for perforasjon $(4,5)$. I magesekken er imidlertid denne teknikken standard prosedyre fordi bedre plass gjør prosedyren enklere å utføre samtidig som en tykkere vegg reduserer perforasjonsrisikoen (6) (fig $2 \mathrm{a}-\mathrm{d}$ ).

I tolvfingertarmen bør kun endoskopisk mucosareseksjon benyttes, fordi konsekvensene av å perforere kan gi alvorlige komplikasjoner (7). I spiserøret er det vanligst å benytte en variant av denne metoden (fig 2 $\mathrm{e}-\mathrm{f}$ ), men avhengig av lesjonens størrelse samt egne erfaringer og preferanser kan man også bruke endoskopisk submukosal disseksjon (fig $2 \mathrm{~g}-\mathrm{h}$ ).

\section{Fjerning av dyptvoksende svulster}

Endoskopisk submukosal disseksjon kan også benyttes til å fjerne visse submukosale svulster som kan vokse helt eller delvis ned i muskellaget, særlig i magesekken (fig 2 c-d), men da må man kalkulere med økt risiko for perforasjon og være komfortabel med bruk av klips for å lukke eventuelle hull (8). En slik perforasjon er i praksis uttrykk for en såkalt fullveggsreseksjon. Svulsten vokser da for dypt til at den bare kan «skrelles ut». Utstyr som tillater fullveggsreseksjoner i ende- og tykktarm er nylig kommet på markedet (9). I første omgang er dette beregnet på godartede svulster eller svulster med celleforandringer som av ulike grunner ikke lar seg fjerne med endoskopisk mucosaeseksjon eller endoskopisk submukosal disseksjon.

A fjerne mindre kreftsvulster i en tidlig fase med liten risiko for lymfeknutespredning er også fullt mulig. Eksempler på slike svulster kan være adenokarsinomer som bare vokser ned i øvre del av submucosa, små nevroendokrine svulster (NET) og små gastrointestinale stromale svulster (GIST).

\section{Komplikasjoner}

Man må regne med en viss prosentandel perforasjoner når man utfører endoskopisk kirurgi. Egne erfaringer viser en frekvens på ca. $5 \%$, noe som er på linje med tall i større materialer (10). De aller fleste perforasjoner erkjennes og lukkes peroperativt og gir derfor ikke symptomer eller komplikasjoner. Det er utviklet spesialiserte, store klips (OTSC, Ovesco, Tübingen, Tyskland) som kan lukke til dels store hull. Forsinkede perforasjoner som oppdages i ettertid er en mindre vanlig komplikasjon, mens forsinkede blødninger forekommer noe hyppigere. De fleste blødninger er små og krever ingen tiltak, mens noen få er større og må behandles konservativt eller endoskopisk.

\section{Når man påviser kreft i svulsten}

Overfladiske biopsier vil ofte underestimere faktisk histologisk stadium (11). Således finner man ofte mer aggressive celleforandringer inne i svulsten etter at den er fjernet endoskopisk. Det betyr at den endoskopiske reseksjonen også har en viktig diagnostisk verdi i tillegg til at man sparer pasienten for fremtidige kontroller av en svulst med for eksempel lavgradige celleforandringer biopsier. I de spesielle tilfellene hvor man finner kreft i preparatet etter en endoskopisk reseksjon, og dette er fjernet radikalt, må det giøres en tverrfaglig vurdering av behovet for å gjøre supplerende kirurgi med organfjerning. Egne erfaringer viser at man da som regel ikke går videre med kirurgi pga. liten risiko for lymfeknutemetastaser ved tidlig kreft (12), komorbiditet og/eller høy alder hos pasienten. Denne tilnærmingsformen kan ses på som et skritt på veien mot en mer individrettet behandling i kirurgien. Man behandler ikke mer enn det som er nødvendig ut ifra spredningsrisiko og pasientens generelle prognose relatert til alder og komorbiditet.

\section{Endoskopisk kirurgi ved akalasi}

Ved siden av å fjerne svulster i hele magetarm-kanalen kan endoskopisk kirurgi også benyttes til å operere pasienter med akalasi, en tilstand der lukkemuskelen i cardia ikke relakseres ved svelging og det blir en gradvis svekkelse av tubulær peristaltikk og økende dysfagi. Løsningen er å spalte spiserørets nedre lukkemuskel slik at maten lettere passerer over til magesekken. Tradisjonelt gjøres dette ved at man åpent eller laparoskopisk går inn i buken og spalter lukkemuskelen fra utsiden (Hellers myotomi). Ved såkalt peroral endoskopisk myotomi (POEM) kan denne spaltingen gjøres endoskopisk fra innsiden av spiserøret ved å lage en liten spalte i mucosa og deretter en tunnel i spiserørsveggen (13) (e-tab 1). I Norge er det for tiden Medisinsk avdeling, Haukeland universitetssykehus i Bergen som utfører dette inngrepet.

\section{Fremtidige endoskopiske behandlinger}

Ved siden av utvikling av teknikker og utstyr for fullveggsreseksjoner pågår det flere studier med utprøvning av ulike endoskopiske teknikker for både antireflukskirurgi og for overvektskirurgi. Endoskopisk utførte koblinger (anastomoser) mellom for eksempel en magesekk med avløpshinder og tarm samt mellom bukabscesser og magesekk, endoskopisk lukking av perforert ulcus, endoskopisk fjerning av pancreasnekroser og endoskopisk spalting av pylorus ved ventrikkelretensjon er allerede en realitet. Under utprøvning er også endoskopiske inn- 


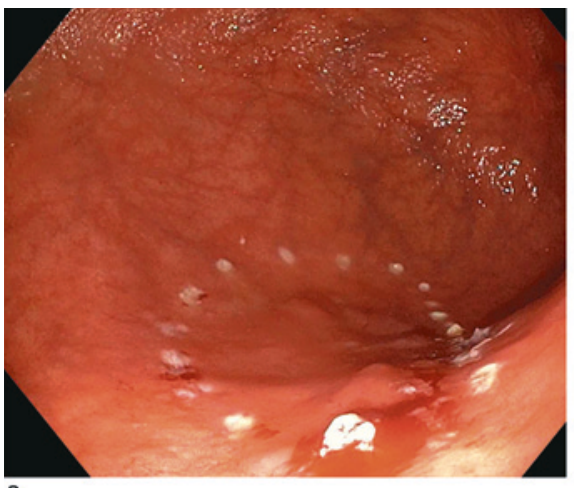

a

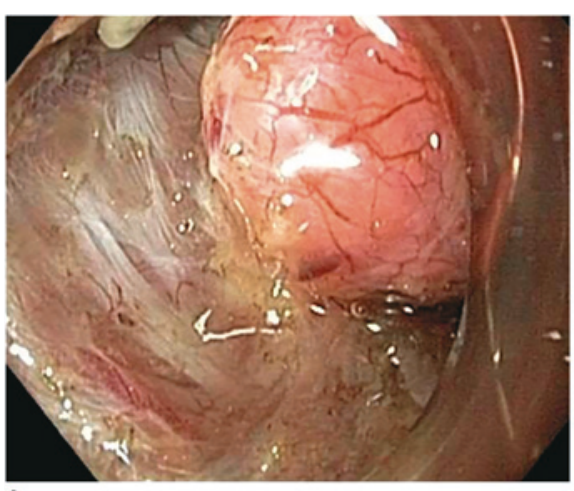

c

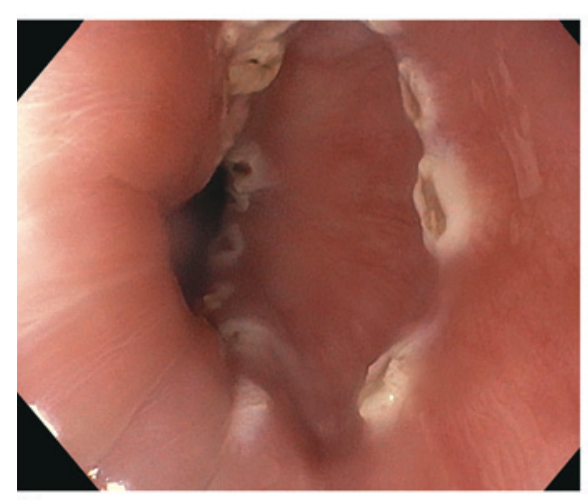

e

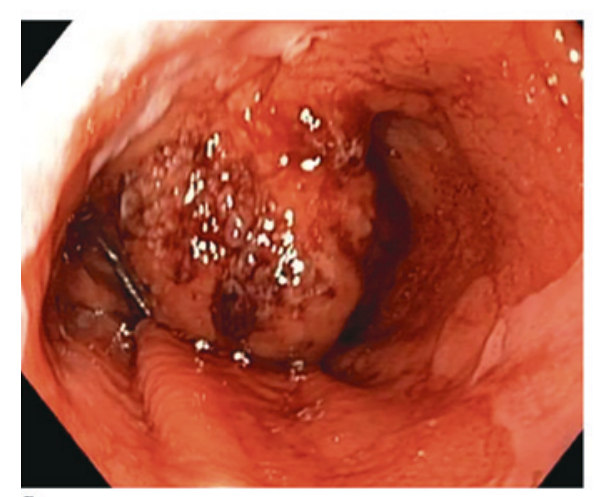

g

Figur 2 al I magesekken ses ofte dysplasi i helt flat mucosa, her avgrenset med hvite diatermimarkeringer. b) En homogen submukøs reseksjonsflate etter endoskopisk submukosal disseksjon bekrefter at det her kun dreier seg om dysplasi og ikke innvekst i dybden som ved invasiv cancer. Den histologiske beskrivelsen av preparatet viste frie reseksjonsrender. c) En gastrointestinal stromal tumor i magesekken etter at mucosa er løftet av tumor og d) Reseksjonstomten etter at tumor er fjernet. Det er ikke nødvendig å lukke mucosa etter reseksjonen. e) Område med påvist dysplasi i spiserøret før og f) området etter en såkalt «plasthette-strikk-slyngereseksjon» utført stykkevis (piecemeall. Alternativt kan lesjoner $i$ spiserøret fjernes med endoskopisk submukosal disseksjon som vist $\mathrm{g}$ ) før reseksjonen og hl etter reseksjonen av en tumor med grov dysplasi grep via de naturlige kroppsåpninger hvor det gjøres inngrep inne i bukhulen med både stive og fleksible skop via incisjoner i kroppens hulorganer som for eksempel magesekk, tykktarm, blære og vagina (natural orifice transluminal endoscopic surgery, NOTES). Videre er det utviklet prototyper på endoskopiske roboter som først og fremst vil kunne bidra til at de endoskopiske reseksjonene vil kunne utføres raskere og enklere. Det er ingen tvil om at den tekniske utviklingen innen endoskopisk kirurgi i dag befinner seg $i$ en tidlig fase og at man vil se store fremskritt i årene som kommer.
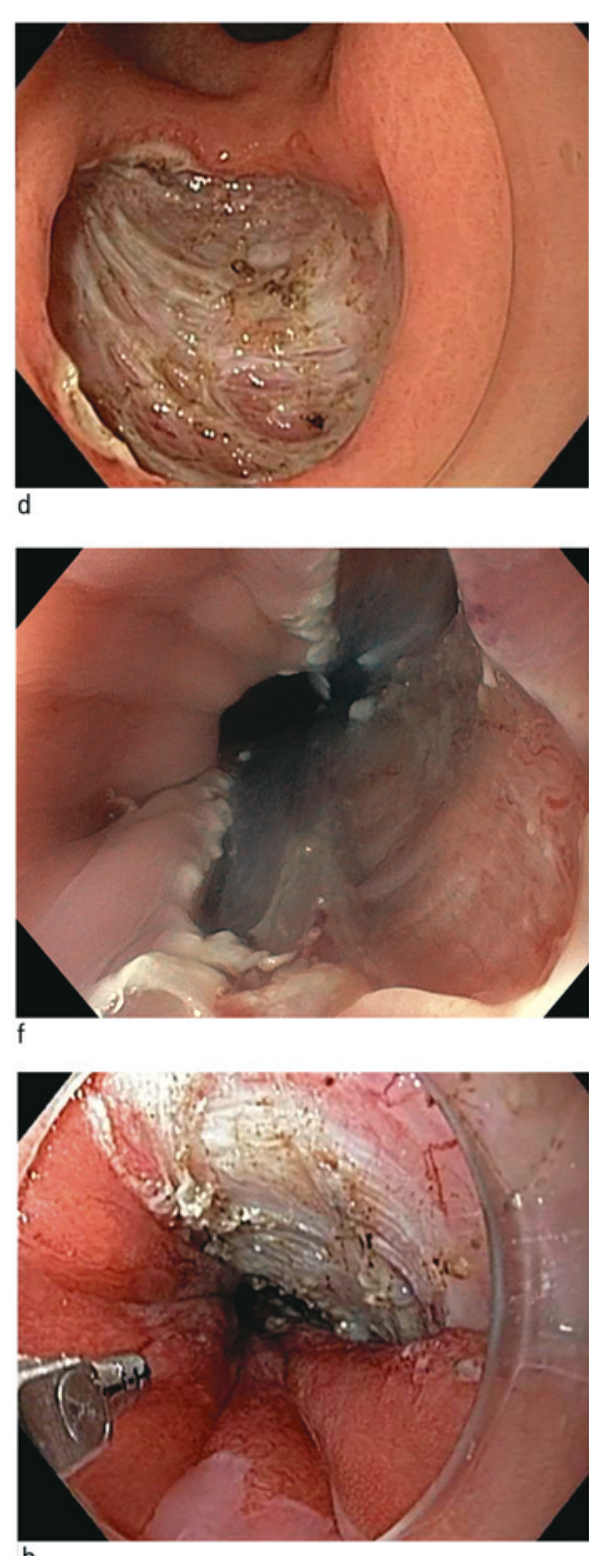

Implementering i vestlige land

Store befolkningskonsentrasjoner, høyere forekomst av tidlig ventrikkelcancer hos japanere samt en uttalt subspesialisering hvor noen dedikerte kirurger eller indremedisinere kun driver med endoskopisk kirurgi, har ført til en rask utvikling og implementering av den endoskopiske kirurgien i Japan og andre asiatiske land. I vestlige land med mindre befolkningsgrunnlag og færre tilfeller per sykehus, blir pasientomfanget begrenset. En vestlig indremedisiner eller kirurg skal gjerne beherske en rekke ulike prosedyrer og operasjoner samt betjene mange ulike arbeidsstasjoner i løpet av arbeidsuken. På den måten blir det ofte for liten tid og mulighet til å utvikle de tekniske ferdighetene som er påkrevet for å beherske endoskopisk kirurgi på en god og trygg måte. Heri ligger det en utfordring både for sentralisering på regionalt nivå samt for en større grad av funksjonsfordeling internt $i$ de enkelte sykehusavdelinger og delvis på tvers av etablerte spesialitetsstrukturer. Flere nyere studier viser at innføring av endoskopisk kirurgi i vestlige land er mulig med akseptable komplikasjonsrater, men vi må regne med lengre operasjonstider $i$ en innføringsfase $(6,14,15)$.

\section{Christian Rushfeldt (f. 1963)}

er dr.med., spesialist i gastroenterologisk kirurgi og overlege.

Forfatter har fylt ut ICMJE-skjemaet og oppgir ingen interessekonflikter.

\section{Khanh Do-Cong Pham (f. 1974)}

er spesialist $\mathrm{i}$ indremedisin og $\mathrm{i}$ fordøyelsessykdommer og er overlege.

Forfatter har fylt ut ICMJE-skjemaet og oppgir ingen interessekonflikter.

\section{Lars Aabakken (f. 1962)}

er spesialist i indremedisin og i fordøyelsessykdommer, professor og leder for Gastrolab. Forfatter har fylt ut ICMJE-skjemaet og oppgir ingen interessekonflikter. 


\section{Litteratur}

1. Gotoda T, Kondo H, Ono H et al. A new endoscopic mucosal resection procedure using an insulationtipped electrosurgical knife for rectal flat lesions: report of two cases. Gastrointest Endosc 1999; 50 $560-3$.

2. Hayashi N, Tanaka S, Hewett DG et al. Endoscopic prediction of deep submucosal invasive carcinoma: validation of the narrow-band imaging international colorectal endoscopic (NICE) classification. Gastrointest Endosc 2013; 78: 625-32.

3. The Paris endoscopic classification of superficial neoplastic lesions: esophagus, stomach, and colon: November 30 to December 1, 2002. Gastrointest Endosc 2003; 58 (suppl): S3-43.

4. Kobayashi N, Yoshitake N, Hirahara Y et al. Matched case-control study comparing endoscopic submucosal dissection and endoscopic mucosal resection for colorectal tumors. J Gastroenterol Hepatol 2012; 27: 728-33.

5. Saito Y, Fukuzawa M, Matsuda T et al. Clinical outcome of endoscopic submucosal dissection versus endoscopic mucosal resection of large colorectal tumors as determined by curative resection. Surg Endosc 2010; 24: 343-52.

6. Rushfeldt C, Aabakken L. Implementation of endoscopic submucosal dissection for gastric lesions in Norway. Scand J Surg 2015; e-publisert 6.8.2015..

7. Bourke MJ. Endoscopic resection in the duodenum: current limitations and future directions. Endoscopy 2013; 45: 127-32.

8. Liu BR, Song JT, Qu B et al. Endoscopic muscularis dissection for upper gastrointestinal subepithelial tumors originating from the muscularis propria. Surg Endosc 2012; 26: 3141-8.

9. Schmidt A, Damm M, Caca K. Endoscopic fullthickness resection using a novel over-the-scope device. Gastroenterology 2014; 147: 740-42.e2.

10. Lee EJ, Lee JB, Lee SH et al. Endoscopic submucosal dissection for colorectal tumors-1,000 colorectal ESD cases: one specialized institute's experiences. Surg Endosc 2013; 27: 31-9.

11. Gondal G, Grotmol T, Hofstad B et al. Biopsy of colorectal polyps is not adequate for grading of neoplasia. Endoscopy 2005; 37: $1193-7$.

12. Wong SK, Jalaludin BB. Henderson CJ et al. Direct umor invasion in colon cancer: correlation with tumor spread and survival. Dis Colon Rectum 2008; 51: $1331-8$.

13. Inoue $H$, Minami H, Kobayashi Y et al. Peroral endoscopic myotomy (POEM) for esophageal achalasia. Endoscopy 2010; 42: 265-71.

14. Spychalski M, Dziki A. Safe and efficient colorectal endoscopic submucosal dissection in European settings: Is successful implementation of the procedure possible? Dig Endosc 2015; 27: 368-73.

15. Thorlacius $\mathrm{H}$, Uedo N, Toth $\mathrm{E}$ Implementation of endoscopic submucosal dissection for early colorectal neoplasms in Sweden. Gastroenterol Res Pract 2013; 2013: 758202.

Mottatt 26.2. 2015, første revisjon innsendt 14.4. 2015, godkjent 1.2. 2016. Redaktør: Tor Rosness 